\title{
Atuação do Nutricionista no Programa Nacional de Alimentação Escolar na Região Sul do Brasil
}

\author{
The role of the nutritionist in the National School Food Program \\ in the southern region of Brazil
}

Rafaela da Silveira Corrêa ${ }^{1}$

Fernanda Camboim Rockett ${ }^{1}$

Priscyla Bones Rocha ${ }^{2}$

Vanuska Lima da Silva ${ }^{2}$

Viviani Ruffo Oliveira ${ }^{2}$

${ }^{1}$ Centro de Estudos em Alimentação e Nutrição, Hospital de Clínicas de Porto Alegre, Universidade Federal do Rio Grande do Sul (UFRGS). R. Ramiro Barcelos 2350, Bom Fim. 90035-903 Porto Alegre RS Brasil.

rafaeladscorrea@gmail.com

${ }^{2}$ Centro Colaborador em Alimentação e Nutrição do Escolar, UFRGS. Porto Alegre RS Brasil.
Abstract The scope of this study was to verify the appropriateness of the minimum numerical benchmark parameters in relation to the mandatory attributions of nutritionists in the South of Brazil in accordance with CFN resolution 465/2010. It is a cross-sectional study with a representative sample of technicians of the $\mathrm{Na}$ tional School Food Program (PNAE) who monitor school food in the southern region of Brazil (Paraná, Santa Catarina and Rio Grande do Sul). Questionnaires were sent electronically to the technicians of PNAE. The results obtained were compared with the recommendations of Resolution CFN 465/2010, regarding the fulfilment of the mandatory attributions and adaptation to the minimum numerical benchmark parameters of this legislation. The results reveal non-compliance in $71.6 \%$ cities of the South of Brazil regarding the number of nutritionists required in accordance with the minimum numerical benchmark parameters of the aforesaid resolution. This discrepancy has an impact on the attributions of nutritionists in the PNAE. These discrepancies highlight the need for partnership-building and intersectoral work to bolster the implementation of PNAE, in addition to highlighting the need to ensure the working conditions to enable the professionals to perform their activities as planned.

Key words Nutritionist, School food, PNAE, Nutrition programs and policies
Resumo O objetivo deste estudo foi verificar a adequação dos parâmetros numéricos mínimos de referência com relação às atribuições obrigatórias do nutricionista da região Sul do Brasil de acordo com a Resolução do CFN 465/2010. Estudo transversal com amostra representativa de Responsáveis Técnicos do PNAE que atuam na alimentação escolar na região Sul do Brasil (PR, SC e RS). Os questionários foram encaminhados por meio eletrônico. Comparou-se o resultado obtido com o preconizado pela Resolução CFN 465/2010, quanto à realização das atribuições obrigatórias e adequação aos parâmetros numéricos mínimos definidos por esta legislação. Os resultados apontam para a não conformidade de $71,6 \%$ dos municípios da Região Sul no que tange o quantitativo de nutricionistas definido pelos parâmetros numéricos mínimos de referência. Esta inadequação se reflete no cumprimento das atribuições do nutricionista no PNAE. Essas inadequações reforçam a necessidade de formação de parcerias e do trabalho intersetorial para o fortalecimento da execução do PNAE, além de ratificarem a necessidade de se garantir condições de trabalho para que o profissional possa exercer suas atividades conforme planejado.

Palavras-chave Nutricionista, Alimentação escolar, PNAE, Programas e políticas de nutrição e alimentação 


\section{Introdução}

O Programa Nacional de Alimentação Escolar (PNAE) completou 60 anos de existência em março de 2015. Caracterizado como a política pública de segurança alimentar e nutricional de maior longevidade do país, o PNAE, ao longo de sua trajetória, passou por diversas alterações, sendo considerado hoje um dos maiores programas na área de alimentação escolar do mundo e o único com atendimento universalizado ${ }^{1,2}$.

As modificações ocorridas na execução do PNAE foram acompanhadas por revisões e atualizações de todo o seu arcabouço legal ${ }^{3}$. Dentre os avanços do programa, destaca-se a descentralização da gestão ocorrida em 1994. A partir desse ano, os estados, os municípios e o Distrito Federal passaram a gerenciar a verba e as ações do PNAE. Concomitante à alteração, ocorreu a inserção do nutricionista nesta política, o qual passou a ser designado como responsável pela elaboração dos cardápios dos programas de alimentação escolar ${ }^{2,4}$.

Após 21 anos da inserção legal do nutricionista no PNAE e diversas alterações nas legislações que o norteiam, o nutricionista se consolidou como Responsável Técnico e importante ator social para o êxito da alimentação escolar. Atualmente, as normativas que determinam os princípios e as diretrizes da política são a Lei 11.947/2009 e a Resolução CD/FNDE $n^{\circ} 26 / 2013^{5,6}$. Em relação ao objetivo do PNAE, segundo a legislação tem-se que:

O PNAE tem por objetivo contribuir para o crescimento e o desenvolvimento biopsicossocial, a aprendizagem, o rendimento escolar e a formação de práticas alimentares saudáveis dos alunos, por meio de ações de educação alimentar e nutricional e da oferta de refeições que cubram as suas necessidades nutricionais durante o período letivo.

Para atingir este objetivo as entidades executoras, secretarias estaduais e municipais de educação, gerenciam o PNAE, e a responsabilidade técnica pela alimentação escolar cabe ao nutricionista. No ano de 2010, o Conselho Federal de Nutricionistas (CFN) publicou a Resolução $\mathrm{n}^{\circ} 465$, estabelecendo os parâmetros numéricos mínimos de referência no âmbito PNAE. Este documento define a carga horária $(\mathrm{CH})$ e o quantitativo de nutricionistas necessário para a execução das atribuições previstas na legislação considerando-se para cálculo o número de alunos atendidos ${ }^{7}$.

Em relação às atribuições do nutricionista no PNAE, compete ao profissional vinculado à
Entidade Executora (EEx) exercer 13 atividades obrigatórias e nove complementares. Das atribuições obrigatórias, destacam-se: realização de diagnóstico do estado nutricional dos estudantes; planejamento, elaboração, acompanhamento e avaliação do cardápio da alimentação escolar; capacitação de recursos humanos; controle de qualidade higiênico sanitário; coordenação e realização de ações de educação alimentar e nutricional (EAN), dentre outras ${ }^{5-7}$.

Embora tenha aumentado expressivamente o numero de nutricionistas vinculados ao PNAE, tanto no Brasil quanto na Região Sul, o atual número de profissionais ainda está aquém do recomendado pelos parâmetros vigentes. Destaca-se que o cumprimento das atribuições técnicas do nutricionista no PNAE relaciona-se ao quantitativo de profissionais no Programa ${ }^{4}$.

Tendo em vista a complexidade e a abrangência do trabalho do nutricionista na alimentação escolar, torna-se necessário verificar a atuação deste profissional em relação à adequação de sua $\mathrm{CH}$ praticada como preconizado na legislação e quanto ao cumprimento por parte dos municípios da região Sul do Brasil em relação aos parâmetros numéricos mínimos definidos pela Resolução CFN 465/2010. Ainda, objetivou-se verificar a execução das atribuições obrigatórias deste profissional pela legislação.

\section{Métodos}

Trata-se de um estudo do tipo observacional de delineamento transversal. O presente estudo foi realizado utilizando o meio eletrônico com amostra representativa de nutricionistas responsáveis técnicos (RTs) pelo PNAE em municípios da região Sul do Brasil, compreendida pelos estados do Paraná (PR), Santa Catarina (SC) e Rio Grande do Sul (RS).

Para o cálculo da amostra, foi realizado um levantamento do número total de nutricionistas RTs vinculados ao setor de alimentação escolar das EEx cadastrados no Fundo Nacional de Desenvolvimento da Educação (FNDE), por meio de listagem fornecida por este órgão. Sendo assim, em março de 2012, existiam 822 nutricionistas cadastrados como responsáveis nos estados da região Sul. Utilizou-se uma margem de erro de 5\%, visando maximizar a variância, e adotouse nível de confiança de 95\%, resultando em um mínimo necessário de retorno de 87 RTs. Estimando-se que a taxa de retorno do questionário fosse de $40 \%$, por se tratar de uma metodologia 
que utiliza o meio eletrônico, calculou-se como necessário o envio do questionário para 218 profissionais.

Posteriormente, foi verificado o número de municípios de cada estado da região Sul do Brasil, e o percentual de representatividade destes, distribuindo-se, assim, o número mínimo de municípios para envio por região para se alcançar a amostra final. A partir deste cálculo, foi obtida a amostra final de retorno de 28 RTs do PR, 21 de SC e 38 do RS. Para sortear a amostra de responsáveis técnicos de municípios para cada estado, foi feito um sorteio aleatório utilizando o programa Pepi versão 4.0.

O questionário para a coleta de dados foi desenvolvido pela equipe do Centro Colaborador em Alimentação e Nutrição do Escolar da Universidade Federal do Rio Grande do Sul (CECANE UFRGS), em parceria com integrantes do FNDE. Esse instrumento foi construído a partir da Resolução CFN 465/2010, focando-se na execução das atividades inerentes ao responsável técnico e sua equipe. Além destas questões, o questionário contemplou também os seguintes fatores: número de escolas do município e modalidades atendidas (educação infantil, ensinos fundamental, médio e educação de jovens e adultos); número de alunos atendidos; e, existência de equipe de apoio no setor de alimentação.

O questionário da pesquisa foi importado para o programa Cubo Mágico Questionário ${ }^{\circledast}$. Os questionários foram encaminhados juntamente com uma carta de apresentação, com a explicação dos objetivos da pesquisa e metodologia adotada. Duas formas de contato foram utilizadas: telefônicos e por e-mail. Os contatos telefônicos foram realizados entre outubro de 2012 e outubro de 2013. Durante o contato telefônico, solicitava-se o e-mail para o envio do questionário e a carta de apresentação sendo o prazo máximo para o retorno das informações solicitadas de 15 dias. Após esse prazo, se o município não tivesse retornado o questionário, um lembrete era enviado. Caso a nova solicitação de retorno não fosse correspondida, novos contatos telefônicos eram realizados. Foram efetuadas até 10 tentativas de contato com a finalidade de obter o retorno do questionário.

Os questionários recebidos passaram inicialmente por uma revisão para a detecção de possíveis falhas de preenchimento. Assim que todos os questionários foram recebidos, o banco de dados foi exportado para uma planilha de Excel ${ }^{\circledast}$. Os resultados foram analisados utilizando-se o software estatístico SPSS versão 18. As variáveis categóricas encontram-se expressas em número absoluto e percentual e as quantitativas em média e desvio padrão, e, quando apropriado, em mediana e intervalo interquartil. Para comparação do número de escolas conforme a frequência de visitas utilizou-se teste de Kruskal-Wallis. Considerou-se significativo o resultado quando $\mathrm{p}<0,05$.

Para verificar a adequação dos parâmetros numéricos mínimos de referência comparou-se o número de nutricionistas evidenciado em cada município, conforme resposta do questionário (RT + Quadro Técnico), como preconizado na Resolução CFN 465/2010. Para análise do quantitativo de nutricionistas necessário para o atendimento da educação infantil, considerou-se a exceção da Resolução.

A análise das atribuições obrigatórias desempenhadas pelos RTs foi por meio da frequência das respostas quanto à realização destas, periodicidade, dentre outros fatores inerentes a cada atribuição que foram também considerados para compor este panorama. Ainda, consideraram-se outros fatores que poderiam influenciar para a realização das atribuições obrigatórias do nutricionista, como existência de quadro técnico, número de escolas do município, atendimento às necessidades específicas, $\mathrm{CH}$ do RT no município e tempo de atuação deste na EEx.

O projeto foi submetido e aprovado pela Comissão de Pesquisa da Faculdade de Medicina e pelo Comitê de Ética em Pesquisa da UFRGS. Por se tratar de uma pesquisa eletrônica, o retorno do questionário preenchido contou como aceite para participar da pesquisa, conforme descrito na carta de apresentação. Destaca-se que o questionário enviado não apresentava identificação do nome do responsável técnico que o respondeu, garantindo-se, desta forma, o anonimato dos participantes da pesquisa. As análises foram feitas mantendo-se o sigilo dos municípios participantes.

\section{Resultados}

Retornaram 116 questionários da região Sul, sendo deste quantitativo 33 do PR (28,4\%), 49 do RS $(42,24 \%)$ e 34 de SC $(29,31 \%)$. O percentual de questionários que foram analisados por estado manteve a proporção da distribuição percentual de nutricionistas lotados em cada um. A caracterização dos municípios, da atuação e do perfil profissional dos nutricionistas RTs do PNAE encontra-se na Tabela 1. O retorno foi superior 
Tabela 1. Caracterização dos municípios, atuação e perfil profissional da amostra de Responsáveis Técnicos do Programa Nacional de Alimentação Escolar dos municípios da região Sul do Brasil.

\begin{tabular}{|c|c|c|c|c|}
\hline Características da Amostra & $\begin{array}{c}\text { n (87) } \\
\text { amostra } \\
\text { calculada }\end{array}$ & $\%$ & $\begin{array}{c}\mathrm{n}(116) \\
\text { amostra } \\
\text { utilizada }\end{array}$ & $\%$ \\
\hline \multicolumn{5}{|l|}{ Estado } \\
\hline Paraná & 28 & 32,18 & 33 & 28,45 \\
\hline Rio Grande do Sul & 38 & 43,68 & 49 & 42,24 \\
\hline Santa Catarina & 21 & 24,14 & 34 & 29,31 \\
\hline \multicolumn{5}{|l|}{ Modalidades de Ensino Atendidas } \\
\hline Educação Infantil & & & 116 & 100 \\
\hline Ensino Fundamental & & & 116 & 100 \\
\hline Ensino Médio & & & 46 & 39,7 \\
\hline Ensino de Jovens e Adultos & & & 75 & 64,7 \\
\hline Escola indígena ou quilombola & & & 2 & 1,7 \\
\hline \multicolumn{5}{|l|}{ Tempo de atuação dos RTs no PNAE na EEx } \\
\hline$\leq 1$ ano ( 1 a 12 meses) & & & 29 & 25 \\
\hline 1 a 2 anos e 6 meses ( 13 a 30 meses) & & & 29 & 25 \\
\hline 2 anos e 7 meses a 5 anos ( 31 a 60 meses) & & & 30 & 25,9 \\
\hline \multirow[t]{2}{*}{$>5$ anos ( $\geq 61$ meses $)$} & & & 28 & 24,1 \\
\hline & & & Mediana & P25 - P75 \\
\hline \multicolumn{5}{|l|}{ População e Escolas Atendidas } \\
\hline Escolas Atendidas & & & 8 & $4-17$ \\
\hline Escolas de Ensino Fundamental & & & 5 & $3-10,75$ \\
\hline Escolas de Educação Infantil & & & 5 & $2-9,75$ \\
\hline Escolas de Ensino Médio & & & 0 & $0-1$ \\
\hline Escolas de Ensino de Jovens e Adultos & & & 1 & $0-1$ \\
\hline Escolares Atendidos & & & 1.200 & $491-2.804$ \\
\hline Escolares Atendidos na Educação Infantil & & & 245,50 & $120-812,75$ \\
\hline \multirow[t]{2}{*}{ Tempo de atuação dos RTs no PNAE na EEx (meses) } & & & 30,5 & $12,5-60,0$ \\
\hline & & & n (116) & $\%$ \\
\hline \multicolumn{5}{|l|}{ Vínculo com a EEx } \\
\hline Concursado & & & 76 & 65,6 \\
\hline Contratado & & & 21 & 18,1 \\
\hline Cargo de confiança & & & 11 & 9,5 \\
\hline RT da empresa contratada & & & 03 & 2,6 \\
\hline Outra resposta & & & 04 & 3,4 \\
\hline Consultor (a) & & & 01 & 0,9 \\
\hline \multicolumn{5}{|l|}{ Carga Horária do RT no PNAE } \\
\hline$<30$ horas & & & 53 & 45,7 \\
\hline$\geq 30$ horas & & & 63 & 54,3 \\
\hline \multicolumn{5}{|c|}{ Atuação do nutricionista em outras Secretarias do município } \\
\hline Não & & & 85 & 73,3 \\
\hline Sim & & & 31 & 26,7 \\
\hline \multicolumn{5}{|l|}{ Atuação do nutricionista no PNAE em outros municípios } \\
\hline Não & & & 103 & 88,8 \\
\hline Sim & & & 13 & 11,2 \\
\hline \multicolumn{5}{|c|}{ Número de Nutricionistas que compõem o Quadro Técnico } \\
\hline Nenhuma & & & 95 & 81,9 \\
\hline Um nutricionista & & & 17 & 14,7 \\
\hline Dois nutricionistas & & & 03 & 2,6 \\
\hline Mais de dois nutricionistas & & & 01 & 0,9 \\
\hline
\end{tabular}

EEx: Entidade Executora; RTs: Responsáveis Técnicos; PNAE: Programa Nacional de Alimentação Escolar. 
à amostra calculada em virtude do questionário ter sido enviado para um número maior de municípios devido à previsão de perdas. Em relação às modalidades de ensino atendidas verificou-se que todos os municípios investigados atendem à Educação Infantil (EI) e ao Ensino Fundamental (EF). Apenas dois municípios (1,7\%) atendem escolas indígenas ou quilombolas.

Metade da amostra de RTs $(\mathrm{n}=58)$ atua no município por tempo igual ou inferior a dois anos e meio. Em relação ao vínculo com a EEx, evidencia-se o predomínio de nutricionistas com vínculo estável, visto que $65,6 \%(\mathrm{n}=76)$ destes são concursados no município pelo qual responderam como RT. A maioria dos profissionais $(88,8 \%, \mathrm{n}=103)$ atua somente no município pelo qual respondeu a pesquisa. No que diz respeito ao quantitativo de nutricionistas, a maioria dos RTs $(81,9 \%, \mathrm{n}=95)$ atua sozinho no município (Tabela 1), isto é, não conta com nenhum profissional no Quadro Técnico (QT).

A Figura 1 apresenta a proporção de municípios com o quadro de nutricionistas adequado ou inadequado aos parâmetros numéricos mínimos definidos pela Resolução CFN 465/20107, bem como a exceção da resolução que trata do atendimento às escolas de educação infantil. Todos os municípios pesquisados neste estudo apresentavam nutricionista. No entanto, a maioria dos municípios da amostra da região Sul (n

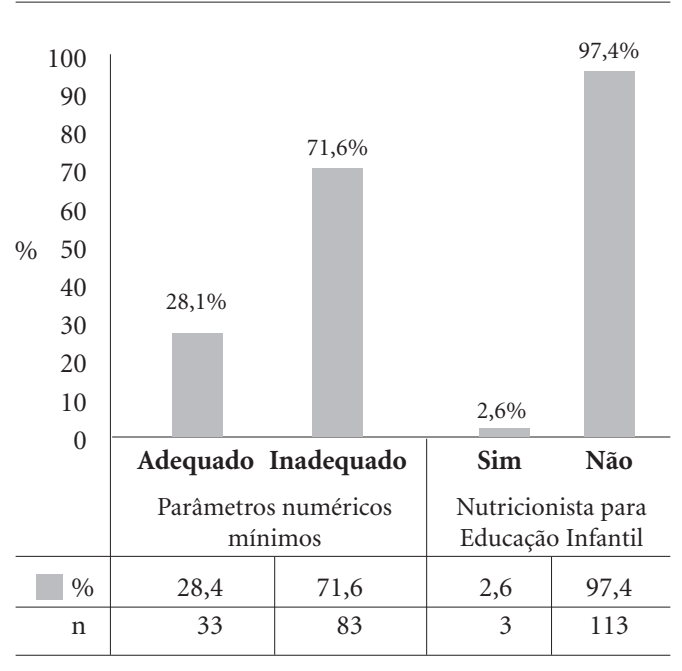

Figura 1. Adequação dos municípios da região Sul do Brasil aos parâmetros numéricos mínimos de referência da Resolução CFN 465/2010.
$=83,71,6 \%)$ está com o quadro inadequado, em relação ao quantitativo recomendado pela resolução referida ${ }^{7}$. Ainda, conforme a Resolução ${ }^{7}$ para atender a modalidade de EI, a EEx deve ter um nutricionista para cada 500 alunos, no entanto, dos municípios investigados 97,4\% ( $\mathrm{n}=$ 112) dos RTs relataram que não há no setor de Alimentação Escolar (AE) nutricionista exclusivo para este fim.

A Tabela 2 apresenta os resultados referentes à realização das 13 atribuições obrigatórias pelos RTs. Ainda, incluiu-se nesta análise o questionamento acerca da realização de visitas às escolas, visto que para o cumprimento pleno das atribuições é necessário que o nutricionista as conheça e as visite, bem como é desejável que estas ocorram com frequência. Em relação às visitas às escolas do município, 99,1\% dos RTs $(\mathrm{n}=115)$ responderam afirmativamente (Tabela 2), sendo que destes, $85,2 \%(\mathrm{n}=98)$ responderam ter visitado todas as escolas do município nos últimos seis meses, $5,2 \%(n=6)$ visitaram mais de metade das escolas, e $8,7 \%(n=10)$ relatou ter visitado metade ou menos da metade das escolas. Somente um nutricionista relatou que não realiza visitas às escolas, no entanto este não justificou sua resposta.

Verificou-se diferença estatisticamente significativa $(\mathrm{p}<0,001)$ do número de escolas dos municípios conforme a frequência de visita (Figura 2), sendo menor o número de escolas dentre os municípios que referiram que visitam com frequência quinzenal a semanal.

Dentre os nutricionistas que realizam o diagnóstico e o acompanhamento do estado nutricional, o método mais utilizado é a aferição de medidas antropométricas $(96,8 \%, \mathrm{n}=90)$. As necessidades nutricionais específicas mais prevalentes dentre os escolares identificadas pelos nutricionistas foram a Intolerância à Lactose e a Diabetes Mellitus, identificada por 52,1\% (n = 49) (Tabela 2).

Embora a maioria dos nutricionistas planeje, elabore, avalie e acompanhe seus cardápios, nem todos os fatores elencados pela legislação são levados em consideração nesta atribuição: 32,5\% ( $\mathrm{n}=37$ ) consideram o diagnóstico nutricional para o planejamento do cardápio; $73,7 \%$ ( $\mathrm{n}=$ $84)$ as referências nutricionais; $19,3 \%(n=22)$ o perfil epidemiológico; e, todos, consideram os hábitos e a cultura alimentar da região 100\% (n =114) e a utilização de produtos da agricultura familiar (AF) 97,4\% (n=111). Grande parte dos nutricionistas $(63,8 \%, \mathrm{n}=74)$ realiza o cálculo do cardápio planejado (Tabela 2). 
Tabela 2. Realização das atribuições obrigatórias pelos Responsáveis Técnicos ( $\mathrm{n}=116,100 \%)$ dos municípios da região Sul do Brasil.

\begin{tabular}{|c|c|c|c|}
\hline & Atribuições & $\mathbf{n}$ & $\%$ \\
\hline \multirow[t]{12}{*}{-} & Realização de visitas às escolas & 115 & 99,1 \\
\hline & \multicolumn{3}{|l|}{ Nos últimos 6 meses, quantas escolas foram visitadas? } \\
\hline & Todas as escolas & 98 & 85,2 \\
\hline & Mais da metade das escolas & 6 & 5,2 \\
\hline & Metade das escolas & 4 & 3,5 \\
\hline & Menos da metade das escolas & 6 & 5,2 \\
\hline & Outra resposta & 1 & 0,9 \\
\hline & \multicolumn{3}{|l|}{ Com que frequência uma escola é visitada? } \\
\hline & Anual a semestral & 12 & 10,5 \\
\hline & Trimestral a mensal & 24 & 20,8 \\
\hline & Quinzenal a semanal & 56 & 48,7 \\
\hline & Sem frequência definida & 23 & 20,0 \\
\hline \multirow[t]{11}{*}{01} & Diagnóstico e o acompanhamento do estado nutricional dos escolares & 93 & 80,2 \\
\hline & \multicolumn{3}{|l|}{ Qual o tipo de diagnóstico nutricional que é realizado com os alunos?(múltipla escolha) } \\
\hline & Antropometria & 90 & 96,8 \\
\hline & Hábitos alimentares & 17 & 18,3 \\
\hline & Consumo alimentar & 12 & 12,9 \\
\hline & \multicolumn{3}{|l|}{ Com que frequência as avaliações nutricionais são realizadas em uma escola? $(n=92)$} \\
\hline & Trimestralmente & 2 & 2,2 \\
\hline & Semestralmente & 14 & 15,2 \\
\hline & Anualmente & 59 & 64,1 \\
\hline & Sem frequência determinada & 14 & 15,2 \\
\hline & Outra resposta & 3 & 3,3 \\
\hline \multirow[t]{7}{*}{02} & Identificação de indivíduos com necessidades nutricionais específicas & 94 & 81,0 \\
\hline & \multicolumn{3}{|l|}{ Quais são as necessidades nutricionais específicas identificadas?(múltipla escolha) } \\
\hline & Hipertensão & 9 & 9,6 \\
\hline & Intolerância à lactose & 49 & 52,1 \\
\hline & Diabetes Mellitus & 49 & 52,1 \\
\hline & Doença celíaca & 28 & 29,8 \\
\hline & Alergias alimentares & 36 & 38,3 \\
\hline \multirow[t]{20}{*}{03} & Planejamento, elaboração, acompanhamento e avaliação do cardápio da alimentação escolar & 114 & 98,3 \\
\hline & \multicolumn{3}{|l|}{ Com qual frequência os cardápios da alimentação escolar são atualizados? } \\
\hline & Mensalmente & 43 & 37,8 \\
\hline & Trimestralmente & 25 & 21,9 \\
\hline & Semestralmente & 17 & 14,9 \\
\hline & Anualmente & 8 & 7,0 \\
\hline & Sem frequência determinada & 13 & 11,4 \\
\hline & Outra resposta & 8 & 7,0 \\
\hline & \multicolumn{3}{|l|}{ Quais parâmetros são considerados ao planejar o(s) cardápio(s) da alimentação escolar? } \\
\hline & Diagnóstico nutricional realizado a partir da avaliação nutricional & 37 & 32,5 \\
\hline & Referências nutricionais de acordo com a faixa etária & 84 & 73,7 \\
\hline & Perfis epidemiológicos da população & 22 & 19,3 \\
\hline & Hábitos alimentares e cultura alimentar de cada localidade & 114 & 100 \\
\hline & Utilização de produtos da AF & 111 & 97,4 \\
\hline & Cardápio anterior & 36 & 31,6 \\
\hline & Cardápio para necessidades específicas & 32 & 28,1 \\
\hline & Período de permanência na escola & 72 & 63,2 \\
\hline & Comunidade escolar Indígena e Quilombola & 2 & 1,8 \\
\hline & \multicolumn{3}{|l|}{ É realizado o cálculo do cardápio planejado? } \\
\hline & Sim & 74 & 63,8 \\
\hline
\end{tabular}


Tabela 2. continuação

\begin{tabular}{|c|c|c|c|}
\hline & Atribuições & $\mathbf{n}$ & $\%$ \\
\hline \multirow[t]{6}{*}{04} & Propor e realizar ações de educação alimentar e nutricional para a comunidade escolar & 105 & 90,5 \\
\hline & Quais são as atividades desenvolvidas com a comunidade escolar? & & \\
\hline & Palestras & 100 & 95,2 \\
\hline & Oficinas culinárias & 43 & 41,0 \\
\hline & Atividades lúdicas/recreativas & 70 & 66,7 \\
\hline & Outras atividades & 6 & 5,2 \\
\hline 05 & Elaborar fichas técnicas das preparações que compõem o cardápio & 39 & 33,6 \\
\hline 06 & $\begin{array}{l}\text { Planejar, orientar e supervisionar as atividades de seleção, compra, armazenamento, } \\
\text { produção e distribuição dos alimentos }\end{array}$ & 112 & 96,6 \\
\hline \multirow[t]{5}{*}{07} & Planejar, coordenar e supervisionar a aplicação de testes de aceitabilidade junto aos escolares & 86 & 74,1 \\
\hline & Quando são aplicados os testes de aceitabilidade? & & \\
\hline & Em função da inserção de preparações novas no cardápio & 72 & 83,7 \\
\hline & Para avaliar a aceitabilidade dos cardápios oferecidos frequentemente & 46 & 53,5 \\
\hline & Em função de alterações inovadoras, em preparações preexistentes no cardápio & 22 & 25,6 \\
\hline 08 & $\begin{array}{l}\text { Interagir com os agricultores familiares e empreendedores familiares rurais e suas } \\
\text { organizações }\end{array}$ & 103 & 88,8 \\
\hline \multirow[t]{9}{*}{09} & Participar do processo de licitação e da compra da AF & 104 & 89,7 \\
\hline & Quais etapas do processo de compra o nutricionista participa? & & \\
\hline & Planejamento da entrega ( logística) & 97 & 86,6 \\
\hline & Levantamento da demanda de gêneros & 94 & 83,9 \\
\hline & Supervisão do recebimento e armazenamento dos produtos & 93 & 83,0 \\
\hline & Elaboração da pauta de compras & 86 & 76,8 \\
\hline & Diagnóstico da produção local (de produtos /quantitativo sazonalidade) & 82 & 73,2 \\
\hline & Avaliação técnica das amostras & 59 & 52,7 \\
\hline & Avaliação dos fornecedores & 56 & 50,0 \\
\hline 10 & Orientação e supervisão da higienização & 116 & 100 \\
\hline 11 & Elaborar e implantar o Manual de Boas Práticas para serviços de alimentação & 51 & 44,0 \\
\hline 12 & Elaborar o plano anual de trabalho do PNAE & 71 & 61,2 \\
\hline 13 & Assessorar o CAE no que diz respeito à execução técnica do PNAE & 108 & 93,1 \\
\hline
\end{tabular}

CAE: Conselho de Alimentação Escolar; PNAE: Programa Nacional de Alimentação Escolar; AF: Agricultura Familiar.

Dentre as ações de EAN para a comunidade escolar, a mais realizada pelos nutricionistas é a palestra $(95,2 \%, \mathrm{n}=100)$. Poucos RTs $(33,6 \%, \mathrm{n}$ = 39) elaboram fichas técnicas das preparações. Dentre os motivos para a realização do teste de aceitabilidade, $83,7 \%(\mathrm{n}=72)$ dos nutricionistas realiza em função da inserção de novas preparações no cardápio (Tabela 2).

Quanto às atividades relacionadas à compra dos gêneros alimentícios, $88,8 \%(\mathrm{n}=103)$ dos nutricionistas interagem com os agricultores familiares e suas organizações, e $89,7 \%(n=104)$ participam do processo de licitação e da compra de produtos da AF. Dentre as etapas que compreendem este processo, 86,6\% $(n=97)$ referiu participar do planejamento da entrega (logística) e somente metade $(50 \%, \mathrm{n}=56)$ realiza avaliação técnica dos fornecedores (Tabela 2).
Todos os nutricionistas orientam e supervisionam as ações referentes à higienização, embora apenas $44 \%(n=51)$ tenha elaborado e implementado o Manual de Boas Práticas nas escolas do município pelo qual é responsável (Tabela 2).

\section{Discussão}

Os resultados do presente estudo revelam inadequação da maioria dos municípios da região Sul do Brasil aos parâmetros numéricos mínimos de referência da Resolução CFN 465/2010. Quanto às 13 atribuições obrigatórias do nutricionista em âmbito do PNAE, verificou-se que apenas duas não são realizadas por mais de metade da amostra, são elas: elaboração de fichas técnicas e do Manual de Boas Práticas. Embora a inconfor- 


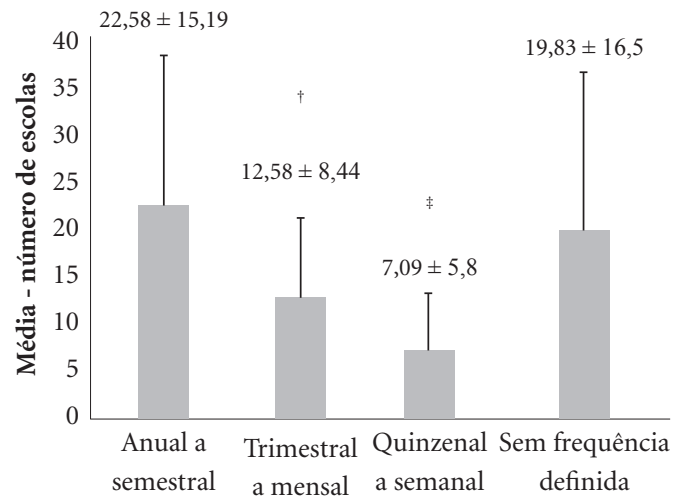

Frequência de visita às escolas

Figura 2. Média do número de escolas visitadas conforme frequência de realização das visitas nos municípios da região Sul do Brasil.

* Diferença da média de escolas visitadas entre o grupo "anual - semestral" e o grupo "quinzenal a semanal" ( $\mathrm{p}<$ $0.001)-{ }^{\dagger}$ Diferença da média de escolas visitadas entre o grupo "trimestral a mensal" e o grupo "quinzenal a semanal" ( $\mathrm{p}<$ 0.023) - ${ }^{\ddagger}$ Diferença da média de escolas visitadas entre o grupo "quinzenal a semanal" e o grupo "sem frequência definida" (p $<0.001)$ - teste de Kruskal-Wallis.

midade do número de nutricionistas não tenha refletido diretamente no cumprimento das atribuições, a qualidade e a frequência da realização das atividades pode ter sido afetada. Além disso, outros fatores influenciam na execução do PNAE além do número de escolares, como, por exemplo, o número de escolas do município e a localização destas (rural/urbana), os quais poderiam ser contemplados nos parâmetros numéricos mínimos.

Devido à falta de pesquisas sobre esta temática, os resultados apresentados foram confrontados com dados pontuais de outros estudos e realizou-se análise comparativa com a legislação vigente.

Todos os municípios pesquisados apresentavam nutricionista RT. Este achado corrobora com a análise realizada nos dados de registro dos nutricionistas cadastrados no sistema do FNDE ao longo dos anos 2003-2011, a qual revelou que a região Sul do Brasil é a que possui maior cobertura de nutricionistas cadastrados no PNAE, sendo o percentual de municípios cobertos no ano de 2011 de $84,5 \%{ }^{4}$. No entanto, cabe destacar que $71,6 \%$ dos municípios possuía o quadro de nutricionista inferior ao recomendado. Análise comparativa do PNAE nos 27 estados e 26 capitais realizada entre 2003 e 2004 já havia destacado a necessidade de maiores investimentos em recursos humanos em todos os níveis: merendeiras, nutricionistas e auditores ${ }^{8}$.

Em relação ao perfil dos nutricionistas, verificou-se que o tempo de atuação no PNAE é relativamente baixo, uma vez que $75,9 \%$ da amostra atua por período inferior a cinco anos. Em estudo prévio realizado pelo CECANE UFRGS com nutricionistas participantes dos cursos de formação, a mediana do tempo de atuação destes foi de quatro anos ${ }^{9}$, similar ao verificado na Região Nordeste por Mello et al. ${ }^{10}$, onde houve predomínio da faixa de atuação de um a cinco anos.

Quanto à forma de contratação do profissional pela Entidade Executora, destacou-se como principal o vínculo “concursado”. Levando-se em consideração a complexidade que permeia a Responsabilidade Técnica do PNAE, frente às atribuições inerentes ao cargo ${ }^{4}$, o tempo de atuação do Nutricionista no PNAE, bem como sua $\mathrm{CH}$ no município podem influenciar na execução das ações ${ }^{10}$. Além disso, a existência do vínculo permanente com a EEx, por meio de concurso público, aumenta a estabilidade do profissional e a possibilidade de desenvolver ações em caráter permanente e de forma contínua.

Quanto ao percentual de nutricionistas que atuam em outros municípios, verificou-se similaridade com os achados do estudo citado anteriormente, realizado no Rio Grande do $\mathrm{Sul}^{9}$, visto que a maioria deles atua somente naquele pelo qual respondeu a pesquisa. Em contraponto, em estudo realizado na região Nordeste ${ }^{10}$, grande parte dos nutricionistas (70,5\%) atuava em outras áreas além do PNAE. Conforme preconizado pela Resolução CFN 465/20107 a CH mínima recomendada do RT é de $30 \mathrm{~h}$, no entanto $45,7 \%$ dos nutricionistas possuem carga horária inferior.

Com o intuito de promover hábitos alimentares saudáveis e a saúde do escolar, o nutricionista assume no PNAE atribuições como a elaboração de cardápios, o acompanhamento da compra dos gêneros alimentícios e a realização de ações de EAN. O crescimento da profissão acompanhou a evolução do programa e, assim, a atuação do nutricionista adquiriu destaque, visto que este profissional contribui para mudanças no hábito alimentar do escolar, na promoção de práticas alimentares saudáveis e na busca da Segurança Alimentar e Nutricional ${ }^{10,11}$.

Em relação às atribuições designadas aos nutricionistas, a maioria dos RTs respondeu que 
realiza avaliação nutricional dos escolares. A importância da avaliação nutricional no PNAE traspõe o diagnóstico nutricional da população. Essa informação pode contribuir, de maneira valiosa, para a reorientação dos objetivos do Programa e para o melhor aproveitamento dos recursos $^{12}$. Conhecer a população com quem se está trabalhando é de grande importância para o planejamento do cardápio e para nortear as ações de EAN. Neste sentido, o Marco de Referência de Educação Alimentar e Nutricional para as Políticas Públicas reforça a necessidade do diagnóstico local, o que inclui conhecer o perfil nutricional da população, visando ao adequado planejamento das ações ${ }^{13}$. Ainda que a maioria dos nutricionistas da Região Sul tenha relatado realizar o diagnóstico e o acompanhamento do estado nutricional dos escolares, somente 31,9\% informaram que o utilizam no planejamento do cardápio.

A Lei no 12.982, de 28 de maio de 2014, ratifica o disposto na Lei no $11.947 / 2009^{5}$, estabelecendo o provimento de alimentação escolar adequada aos alunos portadores de estado ou de condição de saúde específica ${ }^{14}$. A maioria dos nutricionistas RTs relatou que busca identificar os escolares nestas condições, no entanto somente $27,6 \%$ considerou este parâmetro ao elaborar o cardápio. A importância deste eixo vincula-se à busca da garantia ao Direito Humano à Alimentação Adequada, por meio do atendimento diferenciado aos escolares que possuem necessidade específicas ${ }^{6}$.

A elaboração de cardápios é uma das responsabilidades do nutricionista na alimentação escolar. Os cardápios planejados devem levar em consideração as recomendações nutricionais propostas além de atentar-se a outros fatores, como: promoção de hábitos alimentares saudáveis, respeito à cultura alimentar e vocação agrícola de cada localidade ${ }^{5-7}$. Em 98,3\% dos municípios a elaboração e o planejamento do cardápio da alimentação escolar é realizado pelo nutricionista e os fatores citados acima são considerados pela maioria destes. Estudo descritivo realizado por Silva e Souza encontrou percentual semelhante (94,2\%) dentre os municípios do estado de Santa Catarina ${ }^{15}$. O percentual de cardápios supervisionados por nutricionistas na Região Sul do país foi de $84,2 \%$ no estudo realizado por Chaves et al. ${ }^{16}$, sendo, dentre as regiões estudadas pelos autores, a que mais se destacou pela utilização de preparações regionais, visto que $86,5 \%$ dos cardápios contemplavam este tipo de preparação ${ }^{16}$. No contexto da avaliação de políticas e iniciati- vas públicas de SAN, Magalhães ${ }^{17}$ destaca que é fundamental o entendimento da inserção dos alimentos no contexto cultural e social dos alunos nos programas de alimentação escolar.

O planejamento dos cardápios escolares exige embasamento em referências que superam a esfera nutricional: sustentabilidade ambiental, cultural, econômica e social também abarcam a construção dos cardápios ${ }^{18}$. Esta atribuição está dentre os passos elencados para a compra da $\mathrm{AF}^{19}$. Este é um ponto positivo a ser destacado nos resultados desta pesquisa, visto que 95,7\% dos RTs considera para o planejamento do cardápio a utilização de produtos da agricultura familiar e dos empreendedores familiares rurais locais. A Lei 11.947/2009, ao trazer a inovação da utilização de $30 \%$ dos recursos financeiros repassados pelo FNDE no âmbito do PNAE para aquisição de gêneros alimentícios diretamente da agricultura familiar e do empreendedor familiar rural ou de suas organizações ${ }^{5}$, trouxe um novo incentivo para o fortalecimento da AF e sua contribuição para o desenvolvimento social e a economia local ${ }^{15,18,20}$.

Outro importante fator a ser considerado na elaboração dos cardápios escolares diz respeito à aceitabilidade. A inclusão de alimentos que não fazem parte dos hábitos alimentares ou cujas características sensoriais não são atraentes aos escolares prejudica a aceitação da alimentação esco$\operatorname{lar}^{21}$. Embora a aplicação de testes de aceitabilidade seja uma atribuição obrigatória de reconhecida importância, um quarto da amostra (25,9\%), respondeu que não são realizados testes de aceitabilidade. A aceitabilidade dos escolares em relações aos alimentos oferecidos no PNAE é um fator de grande importância na determinação da qualidade do serviço prestado. Esta análise pode evitar o desperdício de recursos públicos na compra de gêneros alimentícios ao passo que identifica os alimentos menos aceitos ou rejeitados pelos escolares $^{22}$. Uma revisão sistemática ${ }^{23}$ com enfoque na aceitação da alimentação escolar reforçou a importância de avaliar os cardápios não somente em relação à sua adequação nutricional, mas também quanto à aceitabilidade. Para tanto, foram elencados os seguintes pontos para aceitação do cardápio: respeito a aspectos culturais, regionais e comportamentais, além do trabalho permanente de EAN como forma de fomentar a formação de hábitos alimentares saudáveis ${ }^{23}$.

Embora sejam observados fatores positivos na elaboração dos cardápios, ainda é necessário que o nutricionista elabore fichas técnicas das preparações, atribuição realizada somente por 
$33,6 \%$ dos RTs. Em conformidade com a Resolução CD/FNDE n²6/2013, os cardápios da alimentação escolar devem ser elaborados a partir das fichas técnicas de preparo, as quais devem conter informações sobre o tipo de refeição, os ingredientes, a consistência, o aporte energético, os macronutrientes, os micronutrientes prioritários (vitaminas A e C, magnésio, ferro, zinco, cálcio) e as fibras ${ }^{6}$. A ficha técnica é um instrumento de planejamento que permite, dentre outros fatores, o controle da produção e dos custos, o cálculo do cardápio, além da descrição do preparo, devido ao detalhamento da técnica e tempo da preparação ${ }^{24}$.

Conforme a legislação vigente, compete ao nutricionista coordenar e realizar, em conjunto com a direção da escola e a coordenação pedagógica, ações de $\mathrm{EAN}^{6}$. Na amostra de RTs do Sul, 90,5\% dos nutricionistas realizam ações de EAN. Quanto às ferramentas utilizadas na prática, foi predominante a utilização de "palestras" para esta finalidade. Para que a EAN seja uma prática contínua e permanente, conforme preconizado pela legislação, é necessário que se discuta a utilização de metodologias de caráter pontual (ex.: palestras). Necessita-se, não somente, de disponibilidade de tempo do nutricionista para o planejamento e a execução das atividades, mas também articulação e formação de parcerias com outros setores, como a direção das escolas e os educadores, de forma que estes se tornem multiplicadores da temática no espaço escolar, inserindo-se desta forma o tema no currículo ${ }^{13}$. A troca de conhecimentos entre professores e nutricionistas ainda é um desafio a ser superado para a inserção e o envolvimento desses profissionais nas ações de $\mathrm{EAN}^{25}$.

No âmbito do PNAE, o profissional responsável pelo planejamento, compra, armazenamento, produção e distribuição dos alimentos é o nutricionista ${ }^{7}$. Diversas etapas compõem esse processo e o sucesso do programa depende da organização e da gestão destas ações. Os alimentos adquiridos devem respeitar o cardápio elaborado e obedecer às proibições e restrições impostas pela Resolução. O nutricionista deve também participar da ordenação de despesas, da gestão e da execução dos contratos administrativos decorrentes do processo licitatório, além de controlar a qualidade dos produtos adquiridos para a clientela do PNAE $^{26}$.

Visando à qualidade e à segurança da alimentação ofertada, é responsabilidade da EEx, no papel do nutricionista responsável, zelar pela higiene e boas práticas em todos os processos da alimentação escolar. Para o controle da qualidade higiênico-sanitária da produção de alimentos o RT deve elaborar e implementar o Manual de Boas Práticas (MBP) nas escolas de seu municí$\mathrm{pio}^{7}$. Menos da metade dos municípios da amostra da região Sul possui MBP específico para cada escola. Em estudo realizado por Cardoso et al. para avaliar a segurança na produção de alimentos em escolas de Salvador (Bahia), nenhuma das 235 avaliadas, atendidas pelo PNAE, possuía $\mathrm{MBP}^{27}$. Tendo por base este cenário, e a importância da realização desta atribuição, o CECANE UFRGS, em parceria com o CECANE UNIFESP, desenvolveu uma ferramenta, de livre acesso, para a elaboração do manual e para o acompanhamento do controle da qualidade da alimentação escolar ${ }^{28}$.

Por fim, para o planejamento de todo o trabalho do nutricionista em âmbito do PNAE, cabe a este profissional a elaboração do plano anual de trabalho, instrumento que consiste em um detalhamento das atividades, projetos e programas a serem desenvolvidos. A elaboração do plano pode auxiliar na organização das atribuições a serem desempenhadas e facilitar o trabalho do RT. Além disso, entende-se como necessário o fortalecimento do vínculo do nutricionista à Entidade Executora. Também, salienta-se a pertinência do diálogo da gestão com o nutricionista para que este tenha pleno conhecimento das atribuições que devem ser exercidas pelo profissional segundo a legislação vigente. Além do diálogo entre gestor e nutricionista, sugere-se a realização de ações que divulguem o trabalho deste profissional no âmbito do PNAE aos gestores e comunidade escolar.

Destaca-se que este estudo é pioneiro ao investigar a atuação do nutricionista do PNAE frente às atribuições a ele designadas na Região Sul do país, e que a literatura a este respeito ainda é escassa. Embora a maioria dos nutricionistas participantes da pesquisa tenha afirmado visitar todas as escolas e cumprir boa parte de suas atribuições, destaca-se que não se investigou a qualidade da execução das atribuições, visto que o presente estudo objetivou conhecer de forma geral a realização das atribuições e a realidade dos municípios. A partir deste diagnóstico inicial, esperamos que esta discussão possa ser ampliada, possibilitando investigações futuras com maior detalhamento acerca da execução de cada uma das atribuições do nutricionista no PNAE. Ainda, a metodologia escolhida para esta pesquisa, por não ter sido presencial, pode ser considerada uma limitação, mas levando em consideração a 
abrangência deste método investigativo, considera-se de grande valia a sua utilização em estudos exploratórios, visto também ao seu custo reduzido e agilidade na coleta de dados.

\section{Considerações finais}

Os resultados apontam para a não conformidade dos municípios da Região Sul no que tange o quantitativo de nutricionistas definido pelos parâmetros numéricos mínimos de referência da Resolução CFN 465/2010. Esta inadequação reflete no cumprimento das atribuições do nutricionista no PNAE. Outros fatores podem ser fa- cilitadores na execução das atribuições inerentes a este profissional, como por exemplo, a presença de outros profissionais no Setor de Alimentação Escolar e na EEx, como técnicos administrativos, técnicos em Nutrição, estagiários, dentre outros. Ressalta-se a necessidade de formação de parcerias e o trabalho intersetorial para o fortalecimento da execução do PNAE. Verifica-se a necessidade da gestão garantir as condições de trabalho preconizadas na legislação para que o profissional possa exercer suas atividades conforme planejado. Assim sendo, espera-se que estes resultados contribuam para subsidiar o planejamento das ações futuras das Entidades Executoras, dos CECANEs, do FNDE e do CFN.

\section{Colaboradores}

RS Corrêa, FC Rockett, PB Rocha, VL Silva e VR Oliveira participaram da concepção do projeto, coleta de dados, análise dos resultados e da redação e revisão do artigo.

\section{Referências}

1. Vasconcelos FAG. Programa Nacional de Alimentação Escolar: limites e possibilidades para a garantia do direito humano à alimentação adequada, saudável e sustentável. Cien Saude Colet 2013; 18(4):906.

2. Peixinho AML. The trajectory of the Brazilian School Nutrition Program between 2003 and 2010: report of the national manager. Cien Saude Colet 2013; 18(4):909-916.

3. Fundo Nacional de Desenvolvimento da Educação (FNDE). Programa Nacional de Alimentação Escolar (PNAE) - Histórico [Internet]. [acessado 2015 mar 15]. Disponível em: http://www.fnde.gov.br/programas/alimentacao-escolar/alimentacao-escolar-historico

4. Chaves LG, Santana TCM, Gabriel CG, Vasconcelos FDAG. Reflexões sobre a atuação do nutricionista no Programa Nacional de Alimentação Escolar no Brasil. Cien Saude Colet 2013; 18(4):917-926.

5. Brasil. Lei n ${ }^{\circ} 11.947$, de 16 de junho de 2009. Dispõe sobre o atendimento da alimentação escolar e do Programa Dinheiro Direto na Escola aos alunos da educação básica; altera as Leis nos 10.880, de 9 de junho de 2004, 11.273, de 6 de fevereiro de 2006, 11.507, de 20 de julho de 2007; revoga dispositivos da Medida Provisória no $2.178-36$, de 24 de agosto de 2001, e a Lei no 8.913 , de 12 de julho de 1994; e dá outras providências. Diário Oficial da União 2009; 17 jun.

6. Brasil. Ministério da Educação (MEC). Fundo Nacional de Desenvolvimento da Educação. Resolução FNDE n ${ }^{\circ}$ 26 , de 17 de junho de 2013. Dispõe sobre o atendimento da alimentação escolar aos alunos da educação básica no âmbito do Programa Nacional de Alimentação Escolar - PNAE. 2013. Diário Oficial da União 2013; 18 jun. 
7. Conselho Federal de Nutricionistas (CFN). Resolução CFN n ${ }^{\circ} 465 / 2010$. Dispõe sobre as atribuições do nutricionista, estabelece parâmetros numéricos mínimos de referência no âmbito do Programa de Alimentação Escolar e dá outras providências. Diário Oficial da União 2010; 25 ago.

8. Stolarski MC, Castro D. Caminhos da Alimentação Escolar no Brasil: análise de uma política pública. Rev Parana Desenvolv 2007; 113:31-58.

9. Scarparo ALS, Oliveira VR, Bittencourt JMV, Ruiz ENF, Fernandes PF, Zys JZ, Moulin CC. Formação para nutricionistas que atuam no Programa Nacional de Alimentação Escolar : uma avaliação da efetividade. Cien Saude Colet 2013; 18(4):1001-1008.

10. Mello AL, Vidal Júnior PO, Sampaio LR, Santos LAS, Freitas MCS, Fontes GAV. Perfil do nutricionista do programa nacional de alimentação escolar na região Nordeste do Brasil. Rev Nutr 2012; 25(1):119-132.

11. Costa EQ, Ribeiro VMB, Ribeiro ECO. Programa de alimentação escolar: espaço de aprendizagem e produção de conhecimento. Rev Nut 2001; 14(3):225-229.

12. Silva MV, Sturion GL, Ometto AMH, Pipitone MAP, Furtuoso MCO. Estado nutricional de escolares e seu acesso a programas sociais em dez municípios brasileiros. Brazilian Soc Food Nutr 2002; 23:33-53.

13. Brasil. Ministério do Desenvolvimento Social e Combate à Fome (MDS). Marco de referência de educação alimentar e nutricional para as políticas públicas. Brasília: MDS; 2012.

14. Brasil. Lei $\mathrm{n}^{\circ} 12.982$, de 28 de maio de 2014. Altera a Lei no 11.947 , de 16 de junho de 2009, para determinar o provimento de alimentação escolar adequada aos alunos portadores de estado ou de condição de saúde específica. Diário Oficial da União 2014; 29 maio.

15. Silva APF, Sousa AA. Alimentos orgânicos da agricultura familiar no Programa Nacional de alimentação Escolar do Estado State of Santa Catarina, Brazil. Rev Nutr 2013; 26(6):701-714.

16. Chaves LG, Mendes PNR, Brito RR, Botelho RB. O programa nacional de alimentação escolar como promotor de hábitos alimentares regionais. Rev Nutr 2009; 22(6):857-866.

17. Magalhães R. Avaliação de políticas e iniciativas públicas de segurança alimentar e nutricional: dilemas e perspectivas metodológicas. Cien Saude Colet 2014; 19(5):1339-1346.

18. Saraiva EB, Silva APF, Sousa AA, Cerqueira GF, Chagas CMDS, Toral N. Panorama of purchasing food products from family farmers for the Brazilian School Nutrition Program. Cien Saude Colet 2013; 18(4):927-935.
19. Brasil. Ministério da Educação (MEC). Fundo Nacional de Desenvolvimento da Educação. Aquisição de produtos da Agricultura Familiar para a Alimentação Escolar. Brasília: MEC; 2014.

20. Ribeiro ALP, Ceratti S, Broch DT. Programa Nacional de Alimentação Escolar (PNAE) e a participação da agricultura familiar em municípios do Rio Grande do Sul. GEDECON 2013; 1(1):36-49.

21. Leme ACB, Philippi ST, Toassa EC. O que os adolescentes preferem: Os alimentos da escola ou os alimentos competitivos? Saúde e Soc 2013; 22(2):456-467.

22. Centro Colaborador em Alimentação e Nutrição do Escolar (CECANE UNIFESP). Manual para aplicação dos testes de aceitabilidade no Programa Nacional de Alimentação Escolar - PNAE. São Paulo: CECANE, UNIFESP; 2010.

23. Oliveira MC, Vassimon HS. Programa Nacional de Alimentação Escolar e sua aceitação pelos alunos: uma revisão sistemática. Investigação 2012; 4080(16):4-10.

24. Akutsu RDC, Botelho RA, Camargo EB, Sávio KEO, Araújo WC. A ficha técnica de preparação como instrumento de qualidade na produção de refeições. Rev Nutr 2005; 18(2):277-279.

25. Domene SMÁ. A escola como ambiente de promoção da saúde e educação nutricional. Psicol USP 2008; 19(4):505-517.

26. Brasil. Ministério da Educação (MEC). Fundo Nacional de Desenvolvimento da Educação. Passos para Executar o Programa Nacional de Alimentação Escolar. Brasília: MEC.

27. Cardoso RDCV, Góes JÂW, Almeida RCDC, Guimarães AG, Barreto DL, Silva SA, Figueiredo KVNA, Vidal Júnior PO, Silva EO, Huttner LB. Programa nacional de alimentação escolar: Há segurança na produção de alimentos em escolas de Salvador (Bahia)? Rev Nutr 2010; 23(5):801-811.

28. Oliveira ABA, Scarparo ALS, Paula CMD, Gonçalves FS, Capalonga R, Cunha DT, Stedefeldt E, Esteca Júnior JC. Guia de Instruções das Ferramentas para as Boas Práticas na Alimentação Escolar. Brasília: Anvisa; 2013.

Artigo apresentado em 04/12/2015

Aprovado em 19/07/2016

Versão final apresentada em 21/07/2016 